\title{
Influência da suplementação com monensina sódica no desempenho produtivo de garrotes mantidos em semi-confinamento
}

\author{
[Influence of sodium monensin supplementation in productive performance of steers in semi \\ confined system]
}

\section{"Artigo Científico/Scientific Article"}

\author{
Enrico Lippi Ortolani ${ }^{1}$, Antonio Humberto Hamad Minervino ${ }^{1 *}$, Carolina Akiko Sato Cabral de Araújo ${ }^{2}$, \\ Alessandra Silva Lima ${ }^{1}$, Francisco Leonardo Costa de Oliveira ${ }^{1}$, \\ Clara Satsuki Mori ${ }^{1}$, Raimundo Alves Barrêto-Júnior ${ }^{3}$
}

\author{
${ }^{1}$ Departamento de Clínica Médica, Faculdade de Medicina Veterinária e Zootecnia (FMVZ), Universidade de São \\ Paulo, São Paulo-SP, Brasil. \\ ${ }^{2}$ Departamento de Medicina Veterinária, Universidade Federal Rural de Pernambuco, Recife-PE, Brasil. \\ ${ }^{3}$ Departamento de Ciência Animal, Faculdade de Medicina Veterinária, Universidade Federal Rural do Semi-Árido, \\ Mossoró-RN, Brasil. \\ *Autor para correspondência/Corresponding author: E-mail: ah.minervino@gmail.com
}

\begin{abstract}
Resumo
Objetivou-se avaliar o efeito da suplementação de monensina sódica sobre os parâmetros produtivos de bovinos em regime de semi-confinamento. Foram utilizados 30 garrotes cruzados, inteiros e com um ano de idade, pesados e divididos em dois lotes homogêneos: controle e suplementado com monensina sódica na dose de $200 \mathrm{mg}$ por animal/dia. Os grupos foram mantidos em pastagem e receberam dieta concentrada calculada em $0,6 \%$ do peso corporal. O estudo teve duração de 60 dias e foram realizadas pesagens dos animais zero, e 60. Amostras de forragem foram obtidas nos dias zero e 30 do estudo para determinação do teor de proteína bruta. Os resultados do ganho de peso, teor de proteína nos capins foram submetidos à análise de variância e teste T de Student para comparação entre os grupos. Não existiram diferenças significativas entre os teores médios de proteína bruta na forragem dos piquetes dos grupos no decorrer do experimento. $\mathrm{O}$ ganho de peso total e diário foram superiores nos bovinos suplementados com monensina $(\mathrm{p}<0,05)$. A suplementação com monensina sódica, na dose de $200 \mathrm{mg} / \mathrm{dia}$, incrementou o ganho de peso de garrotes em 8,6\%. O retorno financeiro obtido com o uso desse aditivo foi compensador em sistemas de semi-confinamento.
\end{abstract}

Palavras-Chave: bovinos; ganho de peso; ionóforos.

\begin{abstract}
The present study evaluated the effects of monensin supplementation on productive parameters of cattle under semi-intensive system. Thirty yearling crossbred bulls were used. The animals were weighed and divided into two groups: control and supplemented with monensin at a dose of $200 \mathrm{mg} / \mathrm{animal} / \mathrm{day}$ for 60 days. Both groups were kept on pasture and fed concentrate according to $0.6 \%$ of their body weights. The study lasted 60 days and was conducted weight of animals on days 0,30 and 60 . Forage samples were collected on days 0 and 30 th to crude protein analysis. The results of weight gain and protein content of grass were subjected to analysis of variance and compared by a Student's $T$ test. There were no significant differences between the average levels of crude protein in grass paddocks of the two groups during the experiment. Total and daily weight gain was higher in cattle supplemented with monensin $(p<0.05)$. Supplementation with monensin at a dose of 200 $\mathrm{mg} /$ day, increased weight gain in $8.6 \%$. The supplementation of monensin was profitable in semi-confined production systems.
\end{abstract}

Keywords: cattle; ionophore; weight gain. 


\section{Introdução}

A pecuária de corte nacional representa um importante segmento econômico para nosso país, levando o Brasil a ser o maior exportador de carne bovina do planeta no momento (Anualpec, 2016). No intuito de se aumentar a produtividade, tem sido indicado o uso de regimes de confinamento e semiconfinamento, a fim de acelerar o ganho de peso e reduzir o tempo de abate, incrementando a taxa de desfrute dos rebanhos (Missio et al., 2009).

Nesses regimes são oferecidas dietas que suplementem os bovinos com concentrados ricos em nutrientes que contenham altos teores de energia e nitrogênio, quer seja ele proveniente de fonte de proteína vegetal ou nitrogênio nãoprotéico, como a uréia (Paixão et al., 2006; Missio et al., 2009).

Para aumentar a eficiência destas dietas são geralmente associados outros aditivos que favoreçam o melhor aproveitamento desses concentrados. Entre eles destaca-se a monensina sódica, ionóforo que seleciona o crescimento de bactérias ruminais mantendo as gram negativas e diminuindo a população de bactérias gram positivas, em especial o Streptococcus bovis, grande formador de ácido láctico a partir do amido (Schelling, 1984; Gomes et al., 2010; Maturana Filho et al., 2010).

Apesar de serem bem conhecidos os efeitos da monensina em sistemas de confinamento, são raros os estudos que avaliem o uso deste aditivo em outros sistemas de manejo, especialmente em condições brasileiras. Deste modo o presente trabalho tem como finalidade avaliar o efeito da suplementação de monensina sódica sobre o ganho de peso e consumo da ração concentrada de garrotes submetidos ao regime de semiconfinamento.

\section{Material e Métodos}

Foram utilizados 30 novilhos cruzados (charolês e nelore), inteiros, com um ano de idade e peso médio inicial de $292 \mathrm{~kg}$. Antes do início do experimento os bovinos foram vermifugados com anti-helmíntico a base de ivermectina (Ivomec Gold $^{\circledR}, 1 \mathrm{~mL} / 50 \mathrm{~kg}$, via subcutânea, Campinas, São Paulo, Brasil) e vacinados contra febre-aftosa (Bovicel ${ }^{\circledR}$, 5mL, via subcutânea, MSD Saúde Animal, São Paulo, SP, Brasil).

Os animais foram pesados e alocados em dois diferentes grupos de acordo com o peso, visando à composição de grupos homogêneos, sendo: grupo Controle e grupo Monensina. O experimento teve duração de 60 dias. Foram realizadas três pesagens individuais de todos os animais no decorrer do experimento, sendo a primeira no dia zero, ao início do experimento, e após 30 e 60 dias, quando então o experimento foi encerrado. Todas as pesagens eram precedidas de jejum alimentar de 13 horas.

No decorrer de todo o experimento, ambos os grupos foram mantidos em um sistema de semiconfinamento em que os animais receberam um suplemento concentrado tendo como base $0,6 \%$ dos respectivos pesos corporais. A quantidade de MS de concentrado oferecida foi corrigida após a pesagem no trigésimo dia de ensaio. Na Tabela 1 está expressa a composição bromatológica da dieta padrão. A análise bromatológica dos ingredientes do concentrado e dos capins foi realizada segundo técnicas tradicionais (Aoac, 1985).

Tabela 1. Ingredientes e composição bromatológica em percentagem na dieta (\%) do concentrado utilizado.

\begin{tabular}{lccccccc}
\hline Ingredientes & Quantidade & MS & PB & EE & NDT & FDN & FDA \\
\hline Polpa cítrica & 78 & 89 & 6,5 & 3,0 & 78 & 26 & 24 \\
Farelo de trigo & 18 & 90 & 15,0 & 4,0 & 73 & 50 & 15 \\
Uréia & 4 & 94 & $*$ & - & - & - & - \\
\hline
\end{tabular}

MS = matéria seca; $\mathrm{PB}$ = proteína bruta; $\mathrm{EE}$ =extrato etéreo; NDT nutrientes digestíveis totais; FDN = fibra em detergente neutro; FDA $=$ Fibra em detergente ácido. * Uréia $=45 \%$ de $\mathrm{N}=281,25$ de equivalente protéico, que representa $11,25 \%$ de PB oriunda da uréia.

No grupo Monensina foi acrescido ao concentrado um suplemento contendo monensina sódica (Rumefort 20\% ${ }^{\circledR}$ - MSD Saúde Animal, São Paulo, Brasil), a fim de proporcionar o consumo total de $200 \mathrm{mg}$ de monensina por animal/dia, dose recomendada para garrotes por Goodrich et al. (1984). Durante a primeira semana de adaptação os bovinos receberam a metade da supracitada dose, atingindo sua totalidade a partir do oitavo dia até o final do experimento no sexagésimo dia. $\mathrm{O}$ suplemento concentrado era dividido em duas porções iguais e oferecida em cochos cobertos às 08:00 e 15:00 horas, diariamente. O consumo do alimento concentrado foi observado diariamente e sobras do concentrado foram pesadas nos dias trinta e sessenta. Os animais recebiam ainda 
suplemento mineral comercial (Fosbovi $20^{\circledR}$, DSM Nutritional Products, São Paulo, SP, Brasil) ad libtum em cocho à parte.

Foi utilizada área total de 48 ha dividida em seis piquetes bem estabelecidos de Braquiaria brizantha, com oito hectares cada, sendo que cada grupo experimental era rotacionado em três piquetes separadamente, com altura de forragem de 35 e $20 \mathrm{~cm}$ para entrada e saída nos piquetes, respectivamente. Nos dias zero e trinta do experimento foram obtidas amostras das pastagens dos diferentes piquetes para determinação do teor de proteína bruta.

Os dados de peso vivo, teor de proteína nos capins foram inicialmente testados quanto sua distribuição pelo teste de Shapiro-Wilks. Como todos os dados apresentaram distribuição normal os mesmos foram submetidos à análise de variância e posteriormente submetidos ao teste T de Student para comparação das médias entre os grupos. Para comparação do ganho de peso dentro de um mesmo grupo entre o dia trinta e sessenta, utilizou-se o teste $\mathrm{T}$ pareado.

\section{Resultados e Discussão}

Não existiram diferenças significativas entre os teores médios de proteína bruta nos capins dos piquetes dos dois grupos no decorrer do experimento, sendo observados valores de $12,1 \%$ $( \pm 0,5)$ para os piquetes do grupo controle e $11,9 \%$ $( \pm 0,4)$ onde pastejavam os animais suplementados com montesina no início do experimento e teores de $11,2 \%( \pm 0,6)$ para o grupo controle e $11,3 \%$ ( \pm $0,5)$ no grupo monensina no dia trinta.

Não foram verificadas sobras de alimento concentrado em nenhum dia no decorrer do experimento, com o término da ingestão do concentrado ocorrendo em no máximo três horas após o oferecimento, em ambos os grupos. Também não foram observados animais que rejeitaram o suplemento ou animais que impediam os demais de chegar ao cocho, sendo que estima-se que todos os animais receberam quantidades similares de concentrado, com pequenas variações que possivelmente não interferiram nos resultados obtidos.

Os dados referentes ao ganho de peso total e diário dos animais estão apresentados na Tabela 2. $\mathrm{O}$ ganho de peso foi superior nos bovinos suplementados com monensina tanto no trigésimo como no sexagésimo dia, bem como na avaliação geral de todo o período $(\mathrm{P}<0,05)$. Não existiram diferenças significativas dentro de cada tratamento $(\mathrm{P}>0,21)$ entre o ganho de peso no dia trinta e no dia sessenta, demostrando ganhos de peso consistentes ao longo dos períodos.

$\mathrm{O}$ ganho de peso percentual médio observado durante o experimento foi 8,6\% superior no grupo suplementado com monensina sódica em relação ao controle, demonstrando o efeito positivo deste aditivo sobre a produtividade. Isto correspondeu a um ganho adicional de 80 $\mathrm{g} /$ garrote/dia ou 4,8 $\mathrm{kg}$ no período de sessenta dias.

Tabela 2. Ganho de peso global (considerando todo o experimento) e diário nos momentos de pesagem dos bovinos dos grupos controle e suplementado com monensina.

\begin{tabular}{|c|c|c|c|c|c|c|}
\hline \multirow{3}{*}{$\begin{array}{l}\text { Tratamento } \\
\text { Controle }\end{array}$} & \multicolumn{6}{|c|}{ Ganho de Peso (kg) } \\
\hline & \multicolumn{2}{|c|}{ Dia 30} & \multicolumn{2}{|c|}{ Dia 60} & \multicolumn{2}{|c|}{ Global } \\
\hline & $28,6^{b}$ & $\pm 2,4$ & $27,1^{b}$ & $\pm 2,3^{\mathrm{b}}$ & $55,7^{\mathrm{b}}$ & $\pm 4,5$ \\
\hline \multirow[t]{3}{*}{ Monensina } & $31,0^{\text {a }}$ & $\pm 3,5$ & $29,6^{\text {a }}$ & $\pm 2,5$ & $60,5^{a}$ & $\pm 4,9$ \\
\hline & \multicolumn{6}{|c|}{ Ganho de Peso diário (kg) } \\
\hline & \multicolumn{2}{|c|}{ Dia 30} & \multicolumn{2}{|c|}{ Dia 60} & \multicolumn{2}{|c|}{ Global } \\
\hline Controle & $0,953^{\mathrm{b}}$ & $\pm 0,08$ & $0,903^{b}$ & $\pm 0,08$ & $0,928^{b}$ & $\pm 0,07$ \\
\hline Monensina & $1,033^{\mathrm{a}}$ & $\pm 0,12$ & $0,986^{\mathrm{a}}$ & $\pm 0,08$ & $1,008^{\mathrm{a}}$ & $\pm 0,08$ \\
\hline
\end{tabular}

Letras diversas entre colunas expressam diferença significativa $(\mathrm{P}<0,05)$.

Bovinos suplementados com monensina sódica fermentam os alimentos mais eficazmente incrementando a produção de propionato, as expensas da diminuição de acetato (Schelling, 1984, Gomes et al., 2010; Maturana Filho et al., 2010). O propionato é melhor utilizado metabolicamente nos tecidos que o acetato e sua produção gera menor gasto de energia no interior do rúmen (Schelling, 1984).
A monensina sódica maximiza o uso de proteína pelo animal, especialmente em bovinos em crescimento, quando os requerimentos deste nutriente são maiores, devido principalmente a síntese de musculatura (Schelling, 1984; Fieser et al., 2007). Essa maximização ocorre de maneira mais evidente quando a fonte dietética de nitrogênio é rica em proteína vegetal e não quando a uréia é a fonte preponderante de nitrogênio (Lana et al., 1997). No presente trabalho, o concentrado 
oferecido continha $19,02 \%$ de proteína bruta, sendo $40,9 \%$ deste originário de proteína vegetal e 59,1\% de nitrogênio não-protéico, oferecido pela uréia. Deste modo, caso a dieta utilizada em sistemas de semi-confinamento utilize maior porcentagem de fonte vegetal de proteína, como subprodutos de soja, o efeito da suplementação com monensina sobre o ganho de peso poderia ser superior aos obtidos no presente estudo.

A suplementação com monensina sódica não interferiu no consumo de concentrado oferecido, visto que os dois grupos ingeriram toda ração disponibilizada diariamente. Uma diminuição no consumo de concentrado poderia interferir negativamente no ganho de peso. Bovinos confinados recebendo dietas ricas em grãos diminuem em média até $10,7 \%$ a ingestão da matéria seca quando são suplementados com monensina sódica em doses superiores a $200 \mathrm{mg}$ por dia (Schelling, 1984). Maturana Filho et al. (2010) verificaram uma redução de 6,3\% no consumo de MS em animais em terminação suplementados com monensina ( $44 \mathrm{mg} / \mathrm{kg}$ de MS), sem causar redução do desempenho produtivo. A diminuição da ingestão de MS em bovinos que recebem monensina não tem sido observada quando a dieta oferecida é exclusiva em forragem (Bergen e Bates, 1984, Oliveira et al., 2005).

Em decorrência do ganho de peso superior em $8,6 \%$ em relação ao grupo controle, especulase que houve mínima ou nenhuma redução do consumo de forragem, no entanto estudos adicionais que avaliem o consumo individual dos animais, tanto do concentrado quando da forragem, são necessários para melhor entendimento dos efeitos da monensina neste sistema produtivo.

No grupo Monensina esse ganho de peso total acumulado foi equivalente a $72 \mathrm{~kg}$ ou 2,4 @ de carcaça. Nos preços médios de 2012 pagos no Estado de São Paulo (R \$ 96,65/@) este grupo de 15 animais suplementados iria gerar uma receita adicional que equivaleria a $\mathrm{R} \$ 231,96$. Se fossemos transferir esses valores para atualidade, nos preços médios da arroba pagos no Estado de SP (R\$ 126,56/@) (Cepea, 2017), esse mesmo grupo geraria uma receita de $\mathrm{R} \$ 303,74$.

O grupo Monensina consumiu $1,8 \mathrm{~kg}$ do produto comercial contendo monensina sódica, de acordo com preços atualizados, a um custo de $\mathrm{R} \$$ $33,2 / \mathrm{kg}$, o que equivale a um gasto de $\mathrm{R} \$ 59,76$ com a utilização do ionóforo. Deste modo, o retorno financeiro do uso do produto foi de $\mathrm{R} \$$ 246,98 , o que representa um ganho de $\mathrm{R} \$ 16,46$ por animal no período de 60 dias. Considerando o grupo de 15 animais, para cada real investido no produto foi obtido retorno de $\mathrm{R} \$ 4,13$.

\section{Conclusão}

A suplementação com monensina sódica, na dose de $200 \mathrm{mg} / \mathrm{dia}$, incrementa o ganho de peso em bovinos mantidos em sistemas de semiconfinamento. $\mathrm{O}$ retorno financeiro obtido com o uso desse aditivo é favorável para o sistema de semi-confinamento avaliado.

\section{Conflito de Interesse}

Os autores declaram não existir conflito de interesse.

\section{Comitê de ética}

Esse estudo não possui protocolo gerado pela Comissão de Ética no Uso de Animais da Faculdade de Medicina e Zootecnia da Universidade de São Paulo (CEUA-FMVZ/USP), pois de acordo com seu regimento interno, a referida Comissão passou a vigorar em dezembro de 2012 e o experimento foi realizado em 2010.

Esse estudo seguiu as recomendações preconizadas pela Lei 11.794 , de 8 de outubro de 2008.

\section{Agradecimentos}

Agradecemos a empresa Vallée S/A, São Paulo, Brasil e a empresa Tortuga Cia. Zootec. Agrária, São Paulo, Brasil que atualmente responde por DSM Nutritional Products, por terem cedido os produtos utilizados nesse estudo.

\section{Referências}

Anuário da pecuária brasileira - Anualpec 2016. Pecuária de Corte. São Paulo: Agra FNP, 2016. 272p.

Association of the Official Analitical Chemist AOAC. Official tentative methods of analysis. $6^{\text {th }}$ ed. Washington: $1985,1015 p$.

Bergen, W.G.; Bates, D.B. Ionophores: Their effect on production, efficiency and mode of action.

Journal of Animal Science, 58:1465-1483, 1984.

CEPEA - Centro de Estudos Avançados em Economia Aplicada Departamento de Economia, Administração e Sociologia ESALQ - Escola Superior de Agricultura Luiz de Queiroz da Universidade de São Paulo (USP). Indicadores da arroba do boi gordo. Disponível em: 
$<$ http://www.cepea.esalq.usp.br/br/indicador/ boi-gordo.aspx >. Acesso em: 01 jul. 2017.

Fieser, B.H.; Horn, G.W.; Edwards, J.T. Effects of energy, mineral supplementation, or both, in combination with monensin on performance of steers grazing winter wheat pasture. Journal of Animal Science, 85:3470-3480, 2007.

Gomes, R.C.; Antunes, M.T.; Nogueira Filho, J.C. M.; Ítavo, L.C.V.; Leme, P.R. Leveduras vivas e monensina em dietas de alto concentrado para bovinos: parâmetros ruminais e degradabilidade "in situ". Revista Brasileira de Saúde Produção Animal, 11(1):202-216, 2010

Goodrich, R.D.; Garrett, J.E.; Gast, D.R.; Kirick, M.A.; Larson, D.A.; Meiske, J.C. Influence of monensin on the performance of cattle. Journal of Animal Science, 58(6):14841498, 1984.

Lana, R.P.; Fox, D.G.; Russell, J.B. Perry, T.C. Influence of monensin on Holstein steers fed high-concentrate diets containing soybean meal or urea. Journal of Animal Science, 75:2571-2579, 1997.

Maturana Filho, M.; Oliveira, M.G.; Del Claro, G.R.; Oliveira, H.P.Q.; Saran Netto, A.; Correia, L.B.; Porcionato, M.A.F.; Zanetti, M.A. Parâmetros sanguíneos e desempenho de bovinos de corte em confinamento, submetidos a diferentes fontes de ionóforos. Revista Brasileira de Saúde Produção Animal, 11(3):772-782, 2010.

Missio, R.L.; Brondani, I.L.; Freitas, L.S. Sachet, R.H.; Silva, J.H.S.; Restle, J. Desempenho e avaliação econômica da terminação de tourinhos em confinamento alimentados com diferentes níveis de concentrado na dieta. Revista Brasileira de Zootecnia, 38(7):1309-1316, 2009.

Oliveira, M.V.M.; Lana, R.P.; Jham, G.N.; Pereira, J.C.; Pérez, J.R.O.; Valadares Filho, S.C. Influencia da monensina no consumo e na fermentação ruminal em bovinos recebendo dieta com teores baixo e alto de proteína. Revista Brasileira de Zootecnia, 34(5):1763-1774, 2005.

Paixão, M.L.; Valadares Filho, S.C.; Leão, M.I.; Valadares, R.F.D.; Paulino, M.F.; Marcondes, M.I. Fonseca, M.A.; Silva, P.A.; Pina, D.S. Uréia em dietas para bovinos: consumo, digestibilidade dos nutrientes, ganho de peso, características de carcaça e produção microbiana. Revista Brasileira de Zootecnia, 35(6):2451-2460, 2006.

Schelling, G.T. Monensin mode of action in the rumen. Journal of Animal Science, 58:1518 1527, 1984. 